From the Subdivisions of Radiology and Perinatology

Department of Child Health, Medical School, University of

Indonesia, Jakarta

\title{
Cardiothoracic Ratio of "Normal" Newborn Babies
}

by

W.T. KARJOMANGGOLO, L.A. TAMAELA and H.E. MONINTJA

In studying the cardiovascular system after birth, it is necessary to determine the radiographic shadow of the heart. Measurements of the transverse diameter of the heart and cardiothoracic ratio are available from several surveys (Backwin and Backwin, 1935; Martin and Friedell, 1952). In Indonesian newborns these are not yet available.

The present paper deals with the measurement of the transverse diameter of the heart and the cardiothoracic ratio in "normal" newborn babies on the first day of life. A comparison has been made on the founth day.

\section{Material and Methods}

A group of 62 "normal" neonates from the neonatal ward, Dr. Tjipto Mangunkusumo Hospital, Jakarta, were radiographed on the first day after birth -some immedi- ately after birth or thereafter up to twenty three hours- and on the fourth day, the day the babies are usually discharged from the hospital.

The eriteria applied to the "normal" newborn included the following cinical findings: 1 . gestation period of 37-42 weeks; 2 . birth weight of more than $2.500 \mathrm{gm} . ; 3$. Apgar score at 1 and 5 minutes of $7-10 ; 4$. respiration rate not more than $60 / \mathrm{min}$.; 5. heart rate not more than $140 / \mathrm{min}$.; 6. uneventful pregnancy, labour and early neonatal life.

The chest roentgenograms were taken with the baby lying supine at a. tube distance of $65 \mathrm{~cm}$ and with exposure factors of $40 \mathrm{Kv}, 200 \mathrm{~mA}$ and $1 / 50$ second. An attempt was made to obtain pictures on inspiration, while the baby was lying quietiy.

From the pictures measurements were made as follows: 1 . The maxi-

Received 19th Sept. 1974. 


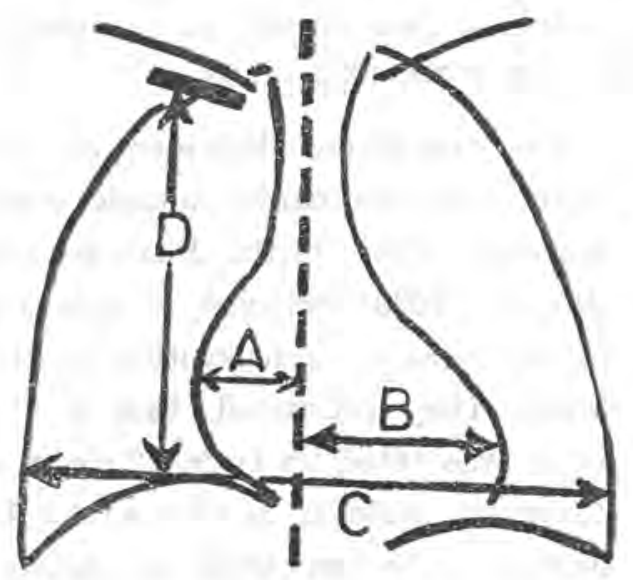

mum transverse diameter of the heart was measured from the sum of the largest distance between the left and right border of the heart to the midline. Care has been taken not to confuse the right border with the right thymic margin, which usually bulged further daterally to the right. 2. The diameter of the thorax was measured from the line drawn parallel to the transverse diameter of the heart at the tip of the right diaphragmatic dome; it extends from the right to the left pleural space. 3 . The length of the thorax was measured from the superior margin of the right first rib posteriorly to the dome of the right half diaphragm. 4. The cardiothoracic ratio was calculated from the maximum diameter of the heart and the diameter of the thorax, expressed as percentage.

\section{Measurements}

$\mathrm{A}+\mathrm{B}:$ The transverse diameter of the heart.

C: The transverse diameter of the thorax.

D : The length of the thorax.

Each film was measured by both authors of the radiological subdivision separately and the data obtained from the observations were analyzed according to the usual statistical methods.

\section{Results}

The difference in observation by both authors of the diameter of the heart, the diameter of the thorax and the length of the thorax on the first and the fourth day are shown (table 1-6). Only in the observation of the transverse diameter of the thorax on the fourth day there was a difference of $4 \mathrm{~mm}$ in $2 \%$ (table 5).

The mean of the transverse diameter of the heart on the first day of life was $50.6 \pm 4.0 \mathrm{~mm}$ and on the fourth day $47.4 \pm 5.4 \mathrm{~mm}$. A comparison between observations of 
the first day and of the fourth day revealed a very significant difference in the diameter of the heart (table 7).

The mean of the transverse diameter of the thorax on the first day of life was $89.3 \pm 3.0 \mathrm{~mm}$ and on the fourth day $91.0 \pm 5.0 \mathrm{~mm}$; a comparison between these observations revealed no significanit difference (table 8).

The mean of the length of the thorax on the first day of life was $51.5 \pm 10.8 \mathrm{~mm}$ and on the fourth day $50.9 \pm 11.6 \mathrm{~mm}$; a companison between these observations revealed no significant difference (table 9).

The mean of the cardiothoracic ratio was $56.3 \pm 4.5 \%$ on the first day of life and $51.9 \pm 4.0 \%$ on the fourth day. A significant difference occurned on comparison between the cardiothoracic ratio on the first and fourth day of life (table 10).

A comparison with other authors of measurements in chest roentgenograms of newborns was made (table 11). No significant difference occurred in the cardiothoracic ratio on the first and on the fourth day of life (table 12).

\section{Diseussion}

Burnard and James (1961) reported, that the measurement of the transverse diameter of the baby at rest has been shown to be reliable within reasonable limits.

The transverse diameter of the heart and the cardiothoracic ratio decrease after birth. Bakwin and Bakwin (1935) believed, it was due to the relative transposition of the heart. They estimated, that if the heart was tilted up from 32 degrees (average angle in newborns) to 45 degrees (average angle in adults) the transverse diameter of the heart would be shortened from $49.7 \mathrm{~mm}$ to $41.4 \mathrm{~mm}$ and the cardiothoracic ratio would be lowered from $0.55 \%$ to $0.46 \%$.

Martin and Friedell (1952) believed that other factors may contribute to the increased transverse diameter of the heart at birth. After the third day there was no significant change in the transverse diameter of the heart and cardiothoracic ratio, indicating that the heart of normal newborn babies by this time had a state of relative stability. There was also an increase in the length of the thorax in the first three days (which was measured from the superior margin of the first right rib posterionly to the dome of the right diaphragm) and there was no significant change thereafter. They believed, that these changes were a reflection of the continued expansion of the lungs during this period. 
Anoxila accompanies incomplete expansion of the lungs and produces myocardial insufficiency with tachycardia and a progressively decreasing systolic discharge. Cardiac dilatation then occurs as a result of such situations. The intra thoracic pressure decreases abnormally with the inspiratory effort to overcome the non expanded lungs. This results in drawing more blood into the thorax which is also probably the cause of the dilation of the heart. According to Kjelberg et al. (1954), the heant volume decreases after birth and reaches a mininum during the fourth day of life. In adults and older children a relationship between heart volume and blood volume has been proved. For the same reason they believe, that the decrease of the heart volume was probably due to changes in blood volume associated with cessation of placentall circulation.

Since in our cases the length of the thorax on the first and the founth day revealed no significant difference, the decrease in heart size $\mathrm{Cn}$ the fourth day after birth was not the resulit of the position of the heant, which is closely related to the position of the diaphragm. There was no significant difference in heart rate and respiration rate on day 1 and on day 4 as a response to anoxia secondary to insufficient expansion of the lungs. The reduction in blood volume associated with cessation of placental circulation resulting in diminishing the heart load, might be the probable explanation. The exaot conclusions concerning the different causes for the decrease in heart size are still open to questions. However, in evaluating the significance of the heart size on the first day of life in normal newborns, it must be kept in mind, that the size will decrease rapidily after several days.

\section{Summary}

Heart size and cardiothoracic ratio have been measured in 62 normal newborn babuies. There was a significant decrease in heart size and cardiothoracic ratio on day 4. The observed values on day 1 were $50.6 \pm$ $4.0 \mathrm{~mm}$ for the heart, $56.3 \pm 4.5 \%$ for the cardiothoracic ratio and on day $4: 47.4 \pm 5.4 \mathrm{~mm}$ for the heart and $51.9 \pm 4.0 \%$ for the cardiothoracic ratio. The probable cause for the reduction in heart size has been discussed. 
TABLE 1: Difference in observations of the diameter of the heart on day 1.

\begin{tabular}{c|c|c}
\hline $\begin{array}{c}\text { DIFFERENCE IN MM } \\
\text { ( D ) }\end{array}$ & $\mathrm{N}$ & PERCENT \\
\hline 0 & 29 & 47 \\
1 & 22 & 35 \\
2 & 6 & 10 \\
3 & 5 & 8 \\
4 & 0 & 0 \\
\hline
\end{tabular}

62 Observations

Mean difference $0.79 \mathrm{~mm}$; Standard Deviation $0.92 \mathrm{~mm}$. Difference in more than $3 \mathrm{~mm}: 0 \%$.

TABLE 2: Difference in observations of the diameter of the thorax on day 1.

\begin{tabular}{c|c|c}
\hline $\begin{array}{c}\text { DIFFERENCE IN MM } \\
\text { ( D ) }\end{array}$ & N & PERCENT \\
\hline 0 & 23 & 37 \\
1 & 29 & 47 \\
2 & 9 & 15 \\
4 & 1 & 1 \\
& 0 & 0 \\
\end{tabular}

62 Observations

Mean difference $0.80 \mathrm{~mm}$; Standard Deviation $0.74 \mathrm{~mm}$. Difference in more than $3 \mathrm{~mm}: 0 \%$. 
TABLE 3: Difference in observations of the length of the thorax on day 1.

\begin{tabular}{c|c|c}
\hline $\begin{array}{c}\text { DIFFERENCE IN MM } \\
\text { ( D ) }\end{array}$ & $\mathrm{N}$ & PERCENT \\
\hline 0 & 19 & 30 \\
1 & 31 & 50 \\
2 & 9 & 15 \\
4 & 3 & 5 \\
& 0 & 0 \\
\hline
\end{tabular}

62 Observations

Mean difference $0.95 \mathrm{~mm}$; Standard Deviation $0.7 \mathrm{~mm}$. Difference in more than $3 \mathrm{~mm}: 0 \%$.

TABLE 4: Difference in observations of the diameter of the heart cm day 4.

\begin{tabular}{c|c|c}
\hline $\begin{array}{c}\text { DIFFERENCE IN MM } \\
\text { ( D ) }\end{array}$ & N & PERCENT \\
\hline 0 & 23 & 37 \\
1 & 20 & 32 \\
2 & 11 & 20 \\
4 & 8 & 11 \\
& 0 & 0 \\
\hline
\end{tabular}

62 Observations

Mean difference $1.06 \mathrm{~mm}$; Standard Deviation $1.04 \mathrm{~mm}$. Difference in more than $3 \mathrm{~mm}: 0 \%$. 
TABLE 5: Difference in the ciservations of the diameter of the thorax on day 4 .

\begin{tabular}{c|c|c}
\hline DIFFERENCE IN MM & N & PERCENT \\
( D ) & & 51 \\
\hline 0 & 32 & 34 \\
2 & 21 & 11 \\
3 & 7 & 2 \\
& 1 & 2 \\
\end{tabular}

62 Observations

Mean difference $0.77 \mathrm{~mm}$; Standard Deviation $0.74 \mathrm{~mm}$. Difference in more than $3 \mathrm{~mm}: 2 \%$.

TABLE 6: Difference in observations of the langth of the thorax on day 4.

\begin{tabular}{c|r|r}
\hline $\begin{array}{c}\text { DIFFERENCE IN MM } \\
\text { ( D ) }\end{array}$ & N & PERCENT \\
\hline 0 & 24 & 39 \\
1 & 28 & 45 \\
2 & 6 & 10 \\
4 & 4 & 6 \\
& 0 & 0 \\
\hline
\end{tabular}

\section{Observations}

Mean difference $0.74 \mathrm{~mm}$; Standard Deviation $0.8 \mathrm{~mm}$. Difference in more than $3 \mathrm{~mm}: 0 \%$. 
TABLE 7 : Results and statistical comparison of the transverse diameter of the heart.

\begin{tabular}{ccccc}
\hline Cases & Day & $\begin{array}{c}\text { Mean } \\
(\mathrm{mm})\end{array}$ & $\mathrm{t}$ \\
\hline 62 & 1 & $50.6 \pm 4.0$ & 3.7541 & $<0.01$ \\
\hline
\end{tabular}

$\mathrm{P}$ less than 0.03 statistically significant.

TABLE 8: Result and statistical comparison of the transverse diameter of the thorax.

\begin{tabular}{cccc}
\hline Cases & Day & $\begin{array}{c}\text { Mean } \\
(\mathrm{mm})\end{array}$ & $\mathrm{t}$ \\
\hline 62 & 1 & $89.3 \pm 3.0$ & 2.2985 \\
62 & 4 & $91.0 \pm 5.0$ & \\
\hline
\end{tabular}

$\mathrm{P}$ less than 0.03 statistically significant.

TABLE 9: Results and statistical comparison of the length of the thorax.

\begin{tabular}{ccccc}
\hline Cases & Day & $\begin{array}{c}\text { Mean } \\
(\mathrm{mm})\end{array}$ & $\mathrm{t}$ \\
\hline 62 & 1 & $51.5 \pm 10.8$ & 0.3000 & $>0.50$
\end{tabular}

P less than 0.03 statistically significant.

TABLE 10 : Result and statistical comparison of the cardiothoracic ratio.

\begin{tabular}{ccccc}
\hline Cases & Day & Mean $(\%)$ & $t$ & P \\
\hline 62 & 1 & $56.3 \pm 4.5$ & 5.7614 & $<0.01$ \\
62 & 4 & $51.9 \pm 4.0$ & &
\end{tabular}

$\mathrm{P}$ less than 0.03 statistically significant. 
TABLE 11 : Comparison of measurements in chest roentgenograms in Newborns.

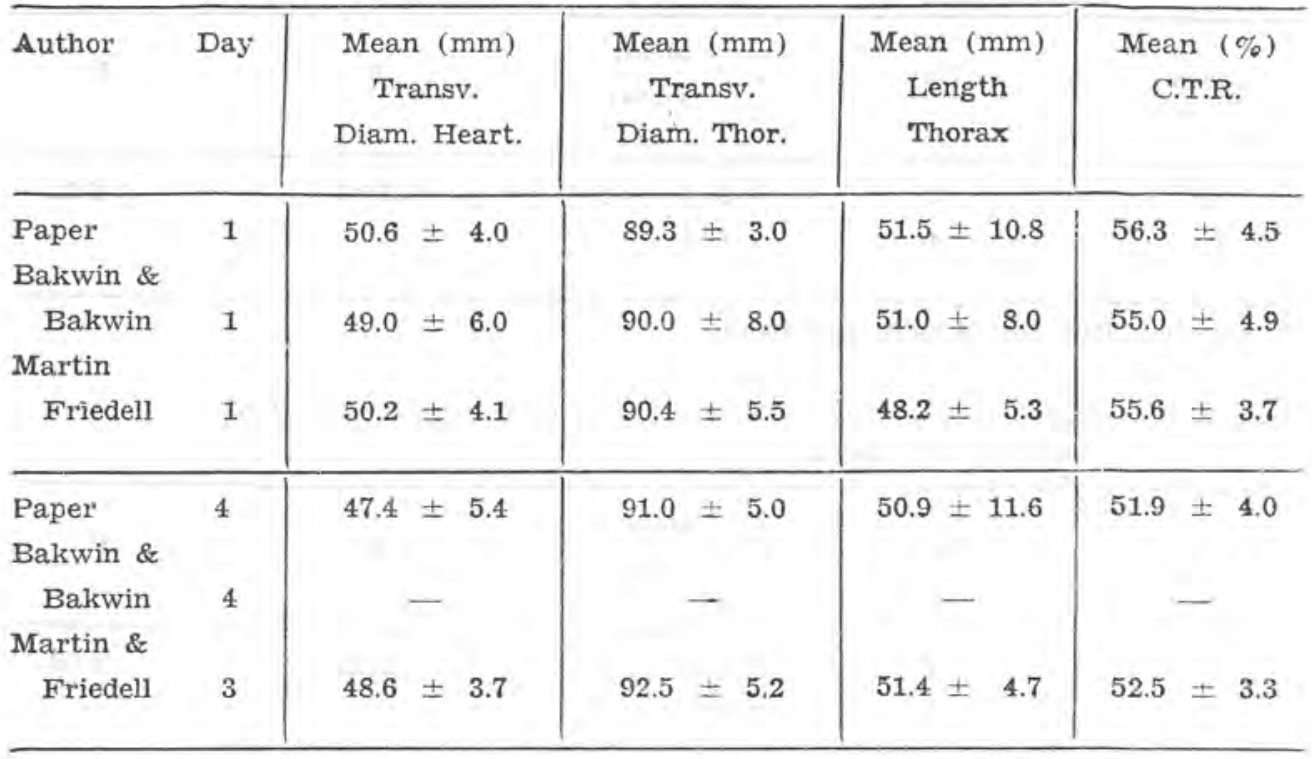

TABLE 12 : Statistical compariscin of the cardiothoracic ratio in Newborns.

\begin{tabular}{|c|c|c|c|c|c|}
\hline Cases & Author & Day & Mean $(\%)$ & $\mathrm{t}$ & $\mathbf{P}$ \\
\hline $\begin{array}{l}62 \\
33\end{array}$ & $\begin{array}{l}\text { Paper } \\
\text { Martin \& } \\
\text { Friedell }\end{array}$ & 1 & $\begin{array}{l}56.3 \pm 4.5 \\
55.6 \pm 3.7\end{array}$ & 0.4602 & $>0.50$ \\
\hline $\begin{array}{l}62 \\
14\end{array}$ & $\begin{array}{l}\text { Paper } \\
\text { Bakwin \& } \\
\text { Bakwin }\end{array}$ & 1 & $\begin{array}{l}56.3 \pm 4.5 \\
55.0 \pm 4.9\end{array}$ & 1.2245 & $>0.10$ \\
\hline $\begin{array}{l}62 \\
33\end{array}$ & $\begin{array}{l}\text { Paper } \\
\text { Martin \& } \\
\text { Priedell }\end{array}$ & 4 & $\begin{array}{l}51.9 \pm 4.0 \\
52.5 \pm 3.3\end{array}$ & 1.1411 & $>0.10$ \\
\hline
\end{tabular}

$\mathrm{P}$ less than 0.03 statistically significant. 


\section{REFERENCES}

1. BAKWIN, M. and BAKWIN, R.M. : Body Build in Infants. VI. Growth of the Cardiac Silhouette and the Thoraco abdominal Cavity. Am. J. Dis. Child., $49: 861$ (1935).

2. BURNARD E.D. and JAMES, L.S. : The Cardiac Silhouette in Newborn Infants: a cinematographic study of the normal range. Pediatr. 27:713 (1961).
3. KJELBERG, S.R., RUDHE, U and ZETTERSTRÖM, R. : Heart Volume Variations in the Neonatal Period. Acta radiol., 42 : 173 (1954).

4. MARTIN J.F. and FRIEDELL, H.L. : The Roentgen Findings in Atelectasis of the Newborn with special Reference to Changes in the Cardiac Silhouette. Am. J. Roentgenol, 57 : 905 (1952). 